\title{
Hazardous material transport accidents: analysis of the D.G.A.I.S. database
}

\author{
S. Bonvicini \& G. Spadoni \\ Department of Chemical, Mining Engineering and Environmental \\ Technologies, Bologna University, Italy
}

\begin{abstract}
In this paper results are presented and discussed about the analysis of the data of hazardous materials road transport accidents reported by the Canadian database D.G.A.I.S. (Dangerous Goods Accident Information System). The records of the database have been subdivided first of all on the basis of the transport phase to which they belong; then they have been classified by the accident typology and, for each type, by its primary cause. Subsequently accidents with hazmat release have been grouped considering the physical state of the spilled substance, in order to determine, basing on the leaked mass, the release categories and their occurrence probabilities. Finally the post-release event trees have been drawn and quantified for flammables. This work has allowed on one hand to determine the major causes of accidents and thus the actions to adopt for reducing the accident frequencies; on the other hand it has been possible to extract data for transport risk analysis, also suggesting useful improvements for bettering the quality of the information recorded by accident databases.
\end{abstract}

Keywords: accident database, event tree, flammables, hazardous materials, road transport, spill, tank truck.

\section{Introduction}

The analysis of an accident database can be performed with two aims. One of these is surely that of "learning from experience" $([1,2])$, that is first of all to understand what are the causes of an accident, in order to pre-emptively undertake those safety measures which will lower the probability it will occur again, and, further, to comprehend what actions have been adopted (or should have been adopted) to limit the consequences of the accident once it has 
happened, in order to face in a suitable way a similar situation which will occur in the future. To confirm this teaching purpose of the databases, in some of them there is a special field for the "learned lessons".

The second reason justifying the examination of a database is that of extracting information useful for quantified risk analysis [3]. Referring to the transport of dangerous goods, useful data are, for instance, the probability that an accident is followed by a release of the shipped chemical, the probability the release being continuous or instantaneous, the probability density distribution of the released mass, the probability of each possible final outcome.

Very often, if transport specific information is not available, these data are obtained from the databases reporting accidents occurred in fixed facilities, like production plants or warehouses. In fact in the process industry it has become routine to collect data about accidental events; indeed the companies with more plants have internal databases for storing and processing these data [1].

However, it is necessary to notice that the equipment of a plant are of a greater variety than those used for transport and also different from them; further the accidents which can occur in a facility are very different from those of a transport vehicle. For this reason for transport risk studies it would be better to use data obtained from accidents occurred during transport.

The analysis of the database D.G.A.I.S. (Dangerous Goods Accident Information System) [4], where information about transportation accidents occurred in Canada is reported, has been performed in order both to determine the main causes of accidents and to extract data for risk analysis. In Italy (and indeed in Europe) there are no transport specific databases. Though, since the Canadian transportation system is very different from the Italian one, because of both the infrastructures and the features of the vehicles, caution should be used when applying Canadian data for Italian case studies.

\section{The D.G.A.I.S. database}

The D.G.A.I.S. database is part of a Canadian national program for public safety in the transport of dangerous goods [5]; this program has been developed by TDG (the Transport Dangerous Goods Directorate) of Transport Canada.

When an accident occurs, the person responsible of the transport or a delegate of him has to compile a form called DOR (Dangerous Occurrence Report), which is then sent to TGD. In this form information is collected about the site and the data of the accident, the transport modality, the type of vehicle, the involved chemicals, the accident causes and consequences.

The accidents records, stored in files, are available on a yearly base; in this research data of 13 years, from 1988 to 2000, have been examined. For each year there are two files: the "accidents file" and the "substances file". In each "accidents file" there are so many records as the accidentals occurrences happened in the year to which the file refers to; in the "substances file" there are so many record as the substances involved in the accidents occurred during the year. Since more chemicals can be involved in a single accident, each record of an "accident file" is in relation with one or more records of the "substance file". 
The research has focused on on-land and in-bulk transportation; in this paper results of the road accidents are reported. 3282 accidents record have been examined, referring to 3431 substance record. The accident records have been subdivided first of all on the basis of the transport phase to which they belong; then they have been classified, for the main transport phase, taking into account the accident typology and its primary cause. Further accidents with hazmat release have been grouped considering the physical state of the substance, in order to determine, basing on the spilled quantities, the release categories and their occurrence probabilities. Finally, further distinguishing the substances on the basis of their hazardous properties, the post-release event trees have been drawn and quantified for flammables.

The categories used for each classification do not always match with those of D.G.A.I.S.; in fact in some cases the classes of the database have been grouped together in order to obtain more meaningful and statistically valid results.

Unfortunately the records are often incomplete, that is many fields have not been filled in; as a consequence, for some classifications only a small number of records has been available, thus affecting the statistical validity of the extracted data.

\section{The analysis of the road accidents}

First of all it has been necessary to determine the transportation phase to which the accident records belong. Three main phases have been taken into account: en-route transit, loading/unloading, rest in a parking area. The distribution of the accidents among these categories is reported in fig. 1.

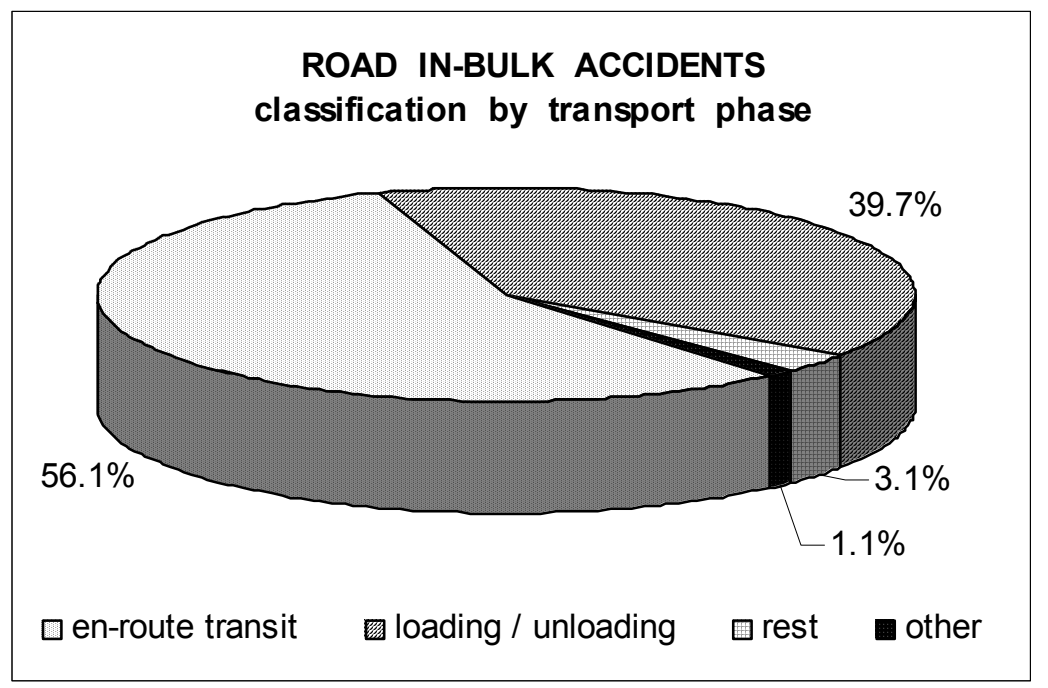

Figure 1: Classification of accidents by phase of transport. 
It is possible to notice that more than half of the accidents (i.e. 56.1\%) occurs during en-route transit; a smaller group occurs during the loading/unloading operations (with a valued of $39.7 \%$ ); finally the percentage of the accidents happened during rest in a parking area or in another transport phase is negligible at all.

Generally tank trucks are loaded and unloaded inside the plant limits under the responsibility of the plant personal; thus the risk of these operations, which are part of the numerous activities performed inside the factory, is usually quantified in the plant risk assessment. Further at plants there is generally a specifically trained emergency team and also specific tools for facing an abnormal situation. For this reason the loading/unloading operations, though they pertain to a tank truck, do not really concern the transport process and thus they have not been considered further in this work.

Focusing on the en-route transit, the accident typologies have been investigated, considering four accident types: collision (with a vehicle or a generic obstacle), turn-over, run-off-road and spontaneous leak form the tank (for instance due to corrosion or from a not perfectly closed valve). The results of this classification are reported in fig. 2 .

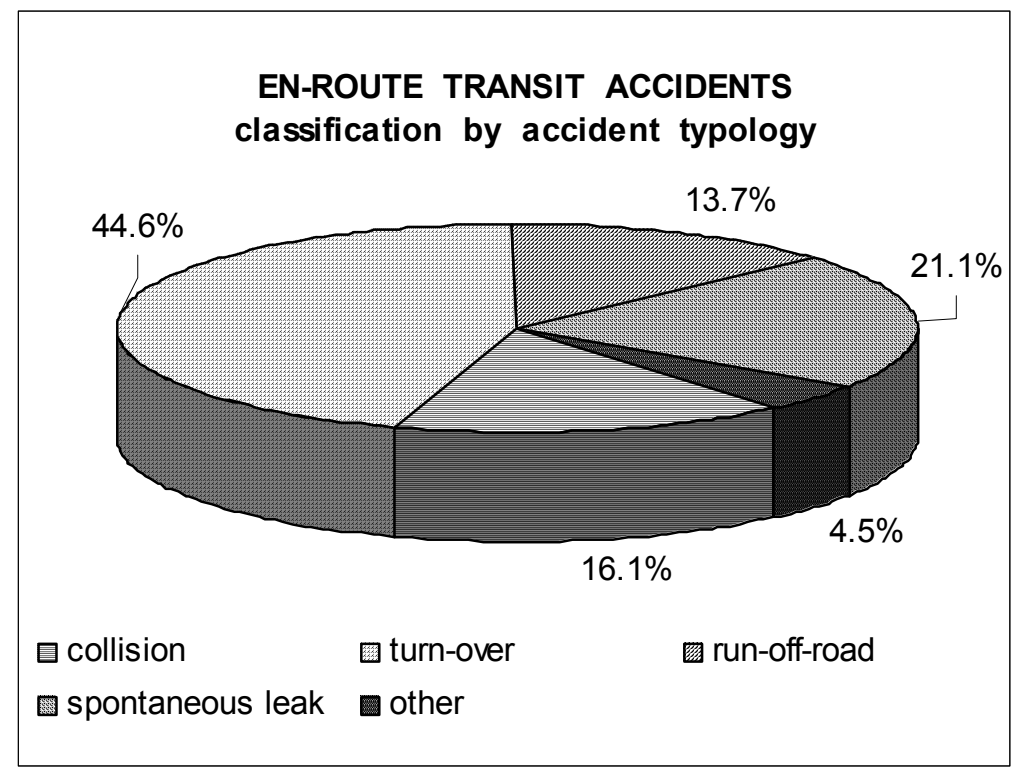

Figure 2: En-route transit accidents: classification by accident typology.

It is possible to notice that, in addition to the traffic accidents, like the collision, the turn-over, the run-off-road, which occur also to vehicles not shipping dangerous goods, the category of the spontaneous leaks (i.e. of the non accident-induced spills) has a great relevance. Subsequently for each accident typology referring to the en-route transit, the primary accident cause has been 
investigated, assuming four primary causes: human error, vehicle failure, tank failure, external event. For human error a wrong action or an omission of the driver is intended (for instance wrong manoeuvres; the non-respect of traffic lights, right of ways, speed limits; grinding halts; driving behaviours not suitable to the road pavement and/or the atmospheric conditions; bad psycho-physical situations of the driver) or an error of the person who has loaded the vehicle (like the overfilling of the tank; the imperfect closure of a valve; the omission of the introduction of specific reaction inhibitors). Vehicle failure stands, for instance for a break-down of the truck, the rupture of an axle, the burst of a tire, the malfunctioning of the braking system. Finally examples of tank failures are leaks due to corrosion, bad welds, cyclic stress, construction defects, overpressure. External events are, for instance, an obstacle or a fire on the road, adverse meteorological conditions, vandalism. The results of this classification are summarized in fig. 3 .

From this figure it results that for all accident typologies human error is the main accident cause, followed by external events; for spontaneous leaks also the tank failure is important. For collision, turn-over and run-off-road events, which occur independently of the transported good, it would be very useful to know the probability an accident being followed by a release; unfortunately the information reported by records does not allow to extract this value. Indeed this datum has a great relevance, since the release frequency, which enters all risk studies, is generally obtained by multiplying the accident frequency and the release probability conditioned to the occurrence of the accident.

Another information which would be important to know is weather a release is continuous or instantaneous; this information too is missing in nearly all records. Though in some records the quantity of spilled substance is reported; this datum has been analysed separately for the liquids and the liquefied pressure gases.

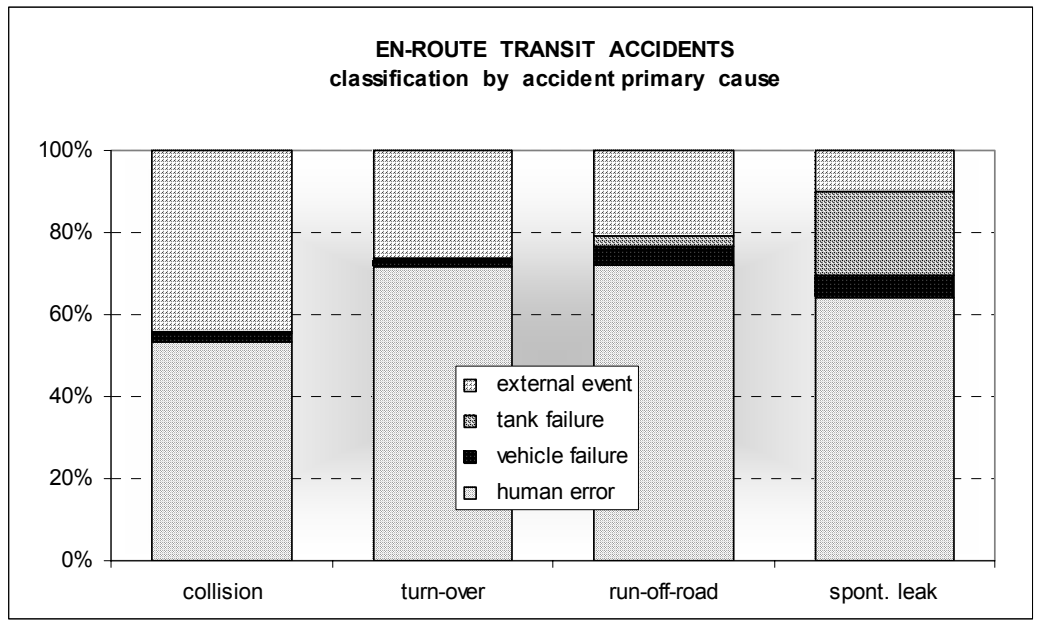

Figure 3: En-route transit accidents: classification by accident primary cause. 
Generally liquids are shipped at ambient conditions of pressure and temperature, while liquefied gases are transported at their vapour pressure at ambient temperature. The different pressure values of liquids and liquefied gases strongly influences the release rate (and thus also the totally released mass) and for this reason a separate classification has been performed for these two types of fluids. Results, referring to 220 liquid records and to 1897 liquefied pressure gas records, are graphed in fig. 4.

It is possible to notice that for liquefied gases all spills are lower than $1 \mathrm{t}$ (ton), while for liquids the spilled quantities are greater, thus allowing the definition of three release categories: $0-1 \mathrm{t}, 1-10 \mathrm{t}$ and 10-100 $\mathrm{t}$.

This fact can be justified by considering the major resistance of the tanks for pressurised chemicals (like those used for liquefied gases) with respect to those designed for atmospheric transports (like those used for liquids). In fact, taking into account that there are no great differences in the tank capacities, the major strength of a pressurized tank determines that accidental holes on this tank will have minor dimensions than those on a pressurized tank: for this reason, though the major pressure, the total released quantity for liquefied gases is smaller than for liquids. In addition the occurrence probability of the release categories becomes lower for greater holes, and this fact too confirms that small leaks are more probable than big ones, as usually assumed in risk analysis studies.

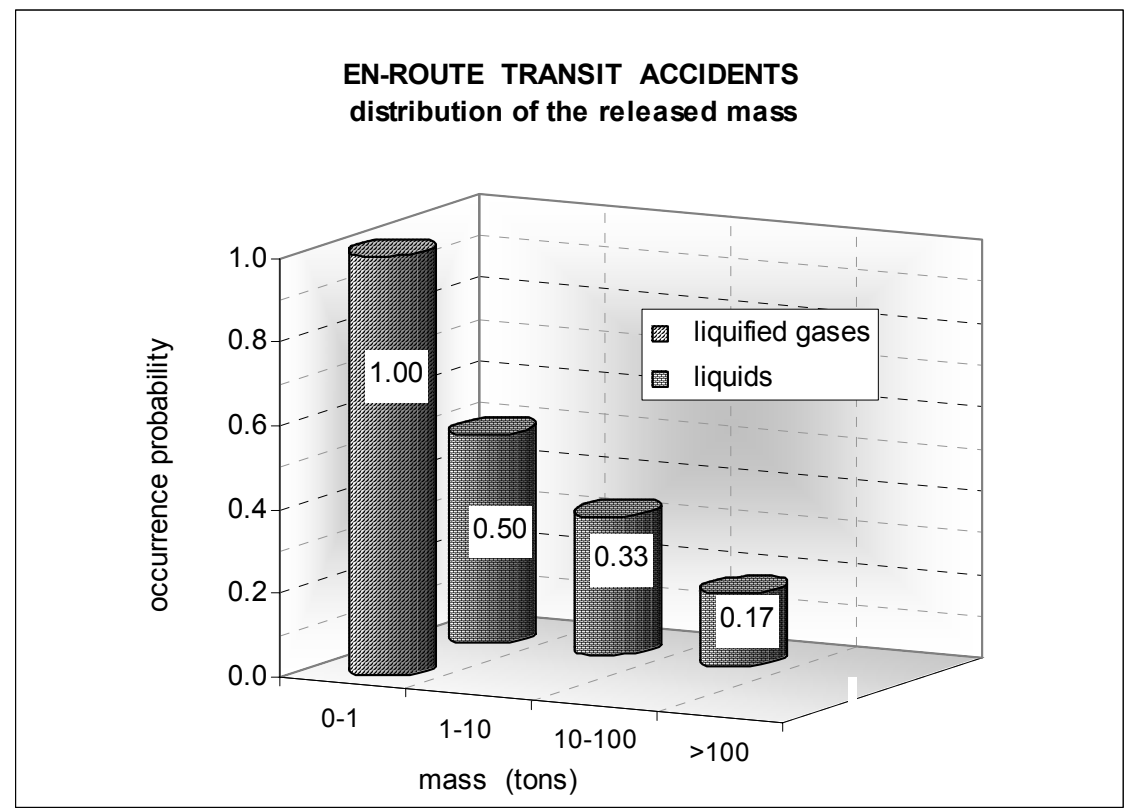

Figure 4: En-route transit accidents: probability density distribution of the released mass. 
For flammable substances it has been possible to draw and quantify also the post-release event trees, distinguishing between liquids and liquefied gases, since the final outcomes of spills involving flammables depend on the storage conditions. In both cases a small number of record has been used for this classification (1844 for liquids; 128 for liquefied gases), since in the major part of the records where a release is reported, no information is given on the final scenario.

In addition for some of these records it has been necessary to make some assumptions in order to assign the outcome reported by the record to a specific final scenario of the event tree; for instance, some records contain the generic information "fire,", without specifying what kind of fire has occurred; though, by reading the information reported in the record, in some cases it has been possible to presuppose a specific type of fire.

The event tree for flammable liquids is reported in fig. 5. It is possible to note that the immediate ignition probability is equal to 0.03 , which is also the value of the delayed ignition probability, thus giving a total ignition probability equal to 0.06 . Further in the case of delayed ignition of a plume evaporated from a pool, it is more probable that there is an explosion (i.e. a VCE, vapour cloud explosion, with probability 0.84 ) than a simple flash-fire (probability 0.16 ).

It's worth noticing that, when performing a transport risk analysis for flammable liquids, it is generally assumed that the final outcome of a delayed ignition is a pool-fire. This assumption implies considering that, also in case of a catastrophic tank truck rupture, the rate of evaporation is so low as to form a very small plume, which does not extend beyond the contour of the pool. Instead from fig. 5 it emerges that the delayed ignition of a plume can produce different and more hazardous scenarios than the pool-fire, and that the delayed ignition probability (equal in percentage value to $0.5 \%+2.4 \%=2.9 \%$ ) is similar to the immediate ignition probability. In addition the fact that the VCE is more probable than the flash-fire is not justifiable; in fact, though the VCEs are favoured, with respect to flash-fires, by the presence of obstacles which obstruct the area occupied by the plume, the poor information reported in the database does not allow to further investigate the influence of this aspect.

In particular the quantified event tree of fig. 5 refers to flammables with a flash-point temperature in the range $-18^{\circ} \mathrm{C}-23^{\circ} \mathrm{C}$; though the probabilities of the event trees of flammables with higher flash-point (and consequently less hazardous) are similar, so that the event tree of fig. 5 can be adopted for all flammable liquids. This fact is difficult to justify, since one could expect that the total ignition probability becomes smaller while increasing the flash-point temperature.

In the case of liquefied gases it would be necessary to consider two event trees, one for continuous leaks and one for instantaneous releases, since the final outcomes are different in these two cases [3]; unfortunately the fact that no information is given in the records about the spill being continuous or instantaneous has not allowed this analysis and only a total event tree has been quantified, which is reported in fig. 6 . 


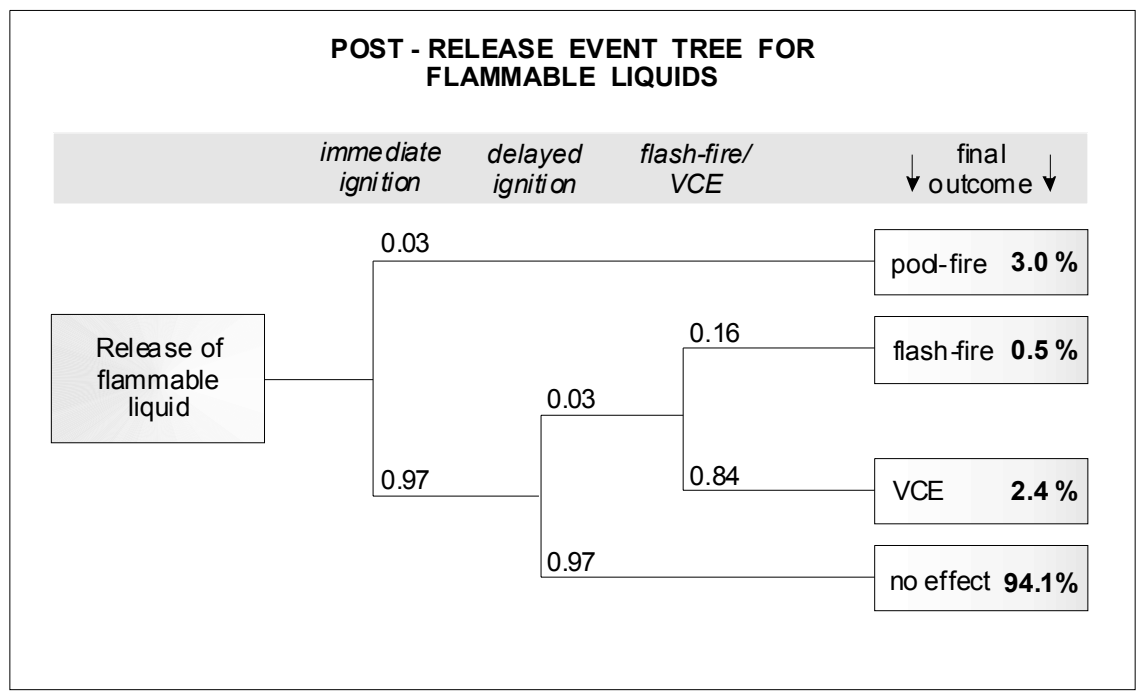

Figure 5: Post-release event tree for flammable liquids.

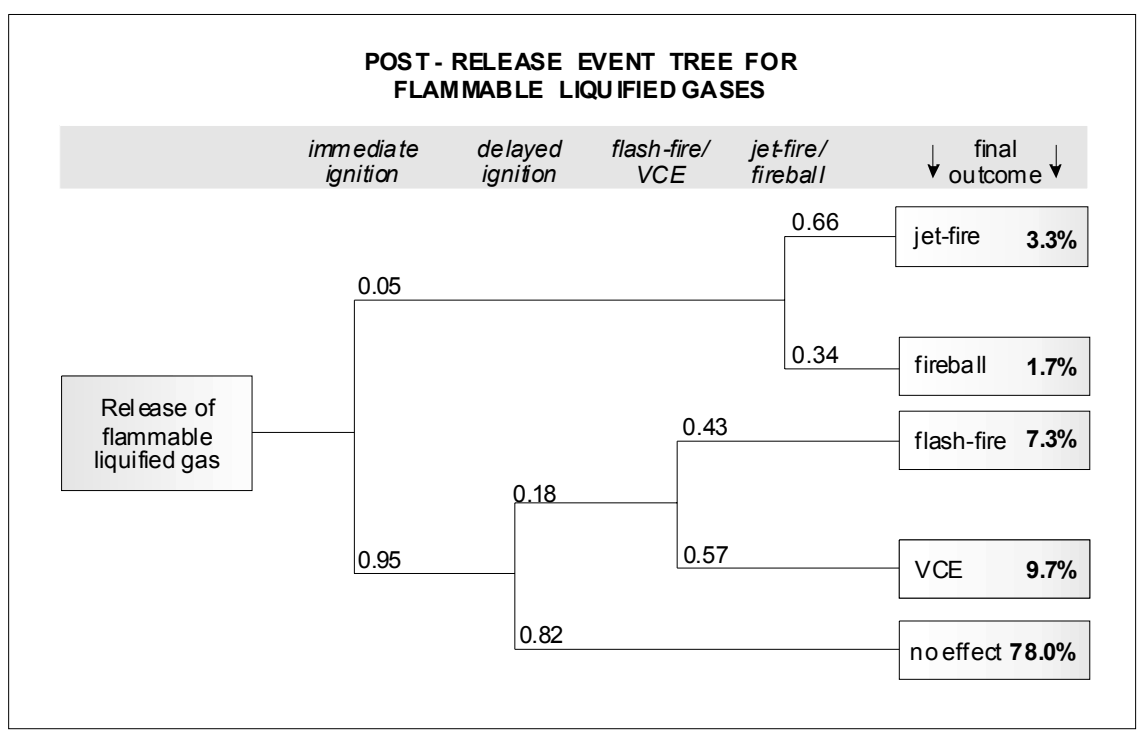

Figure 6: Post-release event tree for flammable liquefied pressure gases.

The percentage total ignition probability is equal to $22.0 \%$, that is greater than the total ignition probability of the liquefied gases, thus confirming the major flammability of liquefied gases with respect to liquids [1].

The probability of occurrence of the VCE and the flash-fire (equal, respectively, to 0.43 and 0.57 ) are not dissimilar as in the case of liquids. This 
fact too is difficult to justify, since the explosion is advantaged, with respect to a simple fire, by the internal turbulence of the cloud, which is surely greater in the case of a plume formed by liquefied gases having at the source a jet, than in the case of a plume developed from an evaporating pool. In addition the fact that the VCE and the flash-fire have similar occurrence probabilities is in contrast with the hypothesis usually assumed in risk analysis, that is to consider negligible the probability of occurrence of the VCE, taking equal to 1, once a delayed ignition occurs, the probability of the flash-fire [6].

\section{Conclusions}

The main result which has emerged form the analysis of the accident primary causes is the great incidence, for all accident typologies, of human error, which varies between $53.2 \%$ and $72.2 \%$.

In the case of spontaneous leaks the error generally occurs while loading the tank truck, and thus is not directly attributable to the shipping company. Though it has to be noticed that the compliance with specific procedures about the handover and acceptance of vehicles, when they are consigned from the sending company to the carrier, in order to verify, for instance, the quantity of chemical which has been loaded (that is the compliance with the filling degree established by regulation), its pressure and temperature conditions, the effective closure of the filling valves and the absence of leaks, could greatly reduce the number of spills which are detected during transport. On the other hand the sudden detection of spills avoids that leaking vehicles began to move, with the hazard that, also because of the strains due to the movement, the leak becomes greater.

A smaller but not negligible percentage of spontaneous leaks is due to the tank failure, that is to the rupture or usury or malfunctioning of the shell of the tank and of the various components of the its equipment, like for instance, the corrosion of the shell, the faulty closure of valves, the wear-out of the gaskets. Since the tank of a truck is not very different form the tanks inside chemical plants, its failure frequency depends on its constructive features, on its time in life and on the period after which the tank is subject to maintenance in order to verify the resistance to pressure and the good functioning of all the servicing equipment. For lowering the occurrence frequency of the spontaneous leaks due to the tank failure, it could be necessary to intensify the tank inspections, in order to detect in advance those components which have to be repaired or substituted.

Indeed the contribution of human error is high for all accident typologies, that is not only for spontaneous leaks, but also for transport accidents; the majority of the traffic accidents is due to the non-compliance with the procedures for driving tank trucks shipping hazardous chemicals. A more rigorous respect of the existing regulations and an increase of the information and training activities for hazmat drivers could drastically lower the occurrence of road accidents.

Looking at the probability data extracted from D.G.A.I.S. for transport risk analysis studies, it is necessary to notice that the information reported by the database is often incomplete and generic, thus not allowing to obtain all data which would be necessary for calculations. To increase the number of the 
records used for the various classifications, it has been necessary to assign the records with generic information to specific categories trough the adoptions of some hypothesis. In addition sometimes it has not been possible to fully understand and justify the differences in the value of some data.

Though the numeric values which have been extracted are uncertain for the above mentioned reason, it seems better to use these data for transportation risk analysis instead of information derived from plants, since data from factories refer to accidents occurred in a totally different context.

At a conclusion of this research, the necessity has become evident to undertake specific initiatives, at a European level, to develop complete and detailed databases for the collection of information about hazmat transport accidents, also in order to obtain reliable data for transportation risk analysis.

\section{References}

[1] Lees, F.P., Loss Prevention in the Process Industries. ButterworthHeinemann: Oxford, 1996.

[2] Kletz, T., Learning from accidents, Butterworths: London, 1988.

[3] CCPS, Guidelines for Chemical Transportation Risk Analysis. AIChE: New York, 1995.

[4] D.G.A.I.S., Dangerous Goods Accident Information System. Canada, 2000.

[5] http://www.tc.gc.ca/tdg/menu.htm

[6] TNO, Department of Industrial Safety, Guidelines for quantitative risk assessment (Purple Book, CPR18E). Sdu Uitgevers: The Hague, 1999. 